\title{
Hypogalactosylation of immunoglobulin $G$ in rheumatoid arthritis: relationship to HLA- DRB1 shared epitope, anticitrullinated protein antibodies, rheumatoid factor, and correlation with inflammatory activity
}

\author{
Christian Schwedler ${ }^{1,2}$, Thomas Häupl', Ulrich Kalus ${ }^{3}$, Véronique Blanchard ${ }^{4}$, Gerd-Rüdiger Burmester ${ }^{1}$,
} Denis Poddubnyy ${ }^{5,6}$ and Berthold Hoppe ${ }^{4,7^{*}}$ (D)

\begin{abstract}
Background: Galactosylation of immunoglobulin $\mathrm{G}(\mathrm{lgG})$ is reduced in rheumatoid arthritis (RA) and assumed to correlate with inflammation and altered humoral immunity. IgG hypogalactosylation also increases with age. To investigate dependencies in more detail, we compared lgG hypogalactosylation between patients with RA, patients with axial spondyloarthritis (axSpA), and healthy control subjects (HC), and we studied it in RA on the background of HLA-DRB1 shared epitope (SE), anticitrullinated protein antibodies (ACPA), and/or rheumatoid factor (RF) status.

Methods: Patients with RA $(n=178)$, patients with axSpA $(n=126)$, and HC $(n=119)$ were characterized clinically, and serum lgG galactosylation was determined by capillary electrophoresis. Markers of disease activity, genetic susceptibility, and serologic response included C-reactive protein (CRP), erythrocyte sedimentation rate (ESR), DAS28, SE, HLA-B27, ACPA, and RF. Expression of glycosylation enzymes, including beta 1-4 galactosyltransferase (B4GALT3) activity, were estimated from transcriptome data for B-cell development (GSE19599) and differentiation to plasma cells (GSE12366).

Results: IgG hypogalactosylation was restricted to RA and associated with increasing CRP levels $(p<0.0001)$. In axSpA, IgG hypogalactosylation was comparable to $\mathrm{HC}$ and only marginally increased upon elevated CRP. Restriction to RA was maintained after correction for CRP and age. Treatment with sulfasalazine resulted in significantly reduced IgG hypogalactosylation ( $p=0.003$ ) even after adjusting for age, sex, and CRP $(p=0.009)$. SE-negative/ACPA-negative RA exhibited significantly less lgG hypogalactosylation than all other strata (vs SE-negative/ACPA-positive, $p=0.009$; vs SEpositive/ACPA-negative, $p=0.04$; vS SE-positive/ACPA-positive, $p<0.02$ ); however, this indicated a trend only after Bonferroni correction for multiple testing. In SE-positive/ACPA-negative RA IgG hypogalactosylation was comparable to ACPA-positive subsets. The relationship between lgG hypogalactosylation and disease activity was significantly different between strata defined by SE (CRP, $p=0.0003$, $\left.p_{\text {Bonferroni }}=0.0036\right)$ and RF $\left(C R P, p<0.0001, p_{\text {Bonferroni }}<0.0012\right)$, whereas ACPA strata revealed only a nonsignificant trend $(p=0.15)$. Gene expression data indicated that the key enzyme for galactosylation of immunoglobulins, B4GALT3, is expressed at lower levels in B cells than in plasma cells.

(Continued on next page)
\end{abstract}

\footnotetext{
* Correspondence: berthold.hoppe@ukb.de

${ }^{4}$ Institute of Laboratory Medicine, Charité - Universitätsmedizin Berlin,

Augustenburger Platz 1, 13353 Berlin, Germany

${ }^{7}$ Institute of Laboratory Medicine, Unfallkrankenhaus Berlin, Warener Straße 7 ,

12683 Berlin, Germany

Full list of author information is available at the end of the article
} 
(Continued from previous page)

Conclusions: Increased IgG hypogalactosylation in RA but not in axSpA points to humoral immune response as a precondition. Reduced B4GALT3 expression in B cells compared with plasma cells supports relatedness to early B-cell triggering. The differential influence of RA treatment on lgG hypogalactosylation renders it a potential diagnostic target for further studies.

Keywords: Rheumatoid arthritis (RA), Axial spondyloarthritis (axSpA), HLA-DRB1 shared epitope (HLA-DRB1 SE), Anticitrullinated protein antibodies (ACPA), Rheumatoid factor (RF), IgG hypogalactosylation, C-reactive protein (CRP), Disease Activity Score in 28 joints (DAS28)

\section{Background}

Rheumatoid arthritis (RA) is a common chronic inflammatory disease of unknown etiology [1]. Because many patients develop joint damage at an early stage after disease onset, it is of special clinical importance to identify and characterize the pathomechanisms in those patients who need early and aggressive therapy [2, 3]. B-cell involvement with production of rheumatoid factor (RF) or anticitrullinated protein antibodies (ACPAs) in about three-fourths of patients with RA significantly influences the clinical course, with more severe joint destruction and more cardiovascular complications $[4,5]$. ACPA and RF are intimately connected to the pathogenesis of RA [6]. Based on this concept, the generation of ACPA or other antibodies against posttranslational modified antigens results in formation of immune complexes (ICs) that are involved in a first wave of inflammation, which is reflected by intraarticular complement activation. The generation of RF that is assumed to be slightly delayed in relation to ACPA results in the production of RF-ICs, which potently activate complement and correspond to a second wave of stronger inflammatory activity. Based on clinical data and on differences in the genetic background of ACPA-positive and ACPA-negative RA, the assumption is that the presence or absence of ACPA defines distinct RA subsets [1]. The genetic background for ACPA in response to different environmental triggers (e.g., smoking) primarily is given by the so-called human leukocyte antigen (HLA)-DRB1 shared epitope (SE) [7-11]. The fragment crystallizable regions (Fc) of ACPA and RF immunoglobulin G (IgG) antibodies carry complex oligosaccharides (Fig. 1) [12], which are structurally diverse and modulate the function and stability of IgG [13-16]. IgG N-glycan diversity has functional consequences (e.g., by modulating interaction with different receptors), thereby influencing antibody-dependent cell cytotoxicity and proinflammatory activity [17-24]. Some decades ago, RA was observed to be associated with reduced galactosylation of whole serum $\operatorname{IgG}[25,26]$, a finding that since has been measured by the so-called serum G0/G1 ratio reflecting the relationship between agalactosylated immunoglobulin G (G0) and monogalactosylated immunoglobulin $G$ (G1) [27]. This IgG hypogalactosylation precedes disease onset by several years and correlates with severity of RA [27-29]. Interestingly, IgG hypogalactosylation normalizes upon remission of RA during pregnancy or under effective treatment [30-33]. It has been described that IgG hypogalactosylation increases with age [17].

Several questions on IgG hypogalactosylation in RA are unaddressed. Comparing the time frame of changes in IgG galactosylation and C-reactive protein (CRP) in RA reveals a striking analogy in that IgG hypogalactosylation [27] and CRP elevations [34] precede RA onset by several years. Thus, the question arises whether IgG hypogalactosylation indicates specific processes involved in humoral autoimmunity or whether it simply reflects inflammatory activity. We addressed this question by analyzing IgG galactosylation in RA as well as in axial spondyloarthritis (axSpA). Spondyloarthritides represent chronic inflammatory diseases without relevant antibody reactivity and only moderate efficacy of B-cell depletion with rituximab $[35,36]$. Because humoral autoimmunity in RA is influenced by HLA-DRB1 SE and is reflected by ACPA and/or RF synthesis, we tested whether these three factors are interrelated with IgG hypogalactosylation and whether the relationship between IgG hypogalactosylation and inflammatory activity differs in RA subsets defined by HLA-DRB1 SE, ACPA, or RF.

\section{Methods}

\section{Patients and control subjects}

Patients with RA were attending the Department of Rheumatology and Clinical Immunology (Berlin). All patients fulfilled American College of Rheumatology criteria for classification of RA [37]. Serum samples from 178 patients with RA were selected according to ACPA and/or SE status with other clinical characteristics blinded. Additionally, 126 patients with ankylosing spondylitis (AS; $n=64$ ) or nonradiographic axial spondyloarthritis (nr-axSpA; $n=62$ ) were included from the GErman SPondyloarthritis Inception Cohort, which was described previously [38]. Samples from blood donors at the Institute of Transfusion Medicine (Berlin) with a similar age and sex 


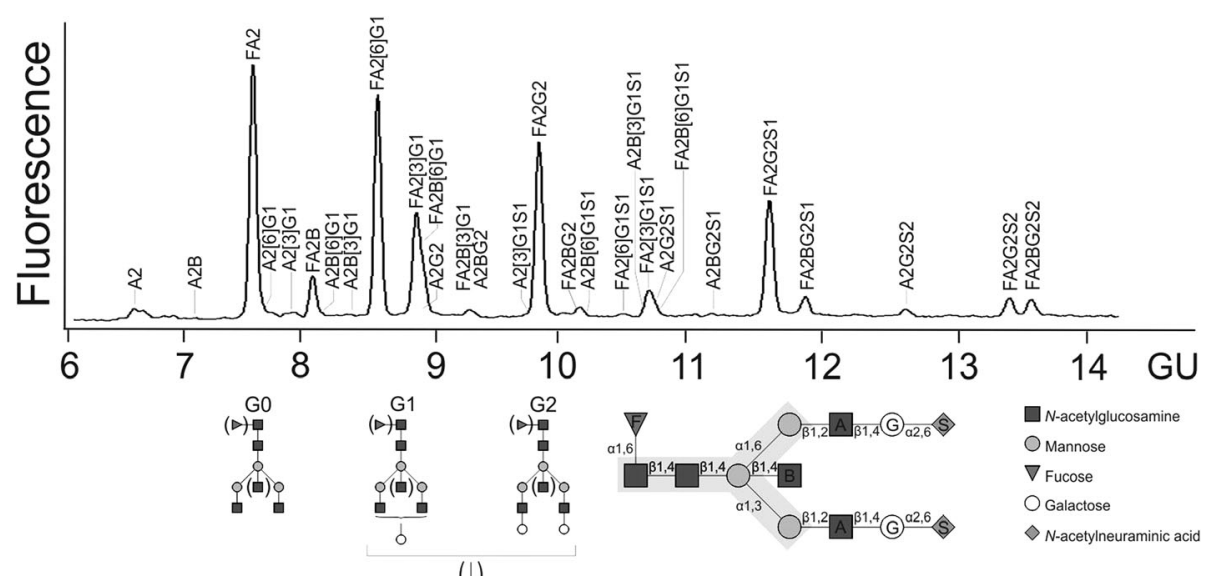

(b)

Fig. 1 Immunoglobulin G (lgG) N-glycan structure and analysis. Composition of N-glycan structures attached to lgG. N-glycans share a common pentasaccharide core consisting of two $\mathrm{N}$-acetylglucosamines (GlcNAc) and three mannose residues (gray background). Major structures are represented by agalactosylated $\lg G(\mathrm{G} 0)$, monogalactosylated $\lg G(\mathrm{G} 1)$, and digalactosylated $\lg \mathrm{G}$ (G2) glycoforms. Above, a representative capillary electrophoresis laser-induced fluorescence detection electropherogram of fragment crystallizable region of lgG N-glycans is shown. F Core fucose, Ax Number of antennary GICNAc, B Bisecting GICNAc linking beta 1-4 to beta 1-3 mannose, Gx Number of beta 1-4 linked galactose (G), [3]G1 and [6]G1 galactose on antenna of alpha 1-3 or alpha 1-6 mannose, respectively, Sx Number of $\mathrm{N}$-acetylneuraminic acids linked to galactose, GU Glucose units

distribution as RA were used as healthy control subjects (HC). None of them presented with symptomatic autoimmune disorders or clinically detectable inflammatory or infectious disease. Baseline characteristics of the study population are summarized in Table 1 and Additional file 1: Table S1. All individuals were included in the study after they provided informed consent. The study was approved by the Charité institutional ethics committee.

\section{Laboratory diagnostics and HLA-DRB1 genotyping}

ACPA were quantified at the time of enrollment with a second-generation enzyme-linked immunosorbent assay (ELISA) using the CCPlus Immunoscan kit (Euro-Diagnostica, Malmö, Sweden) for detection of RA [39]. A cutoff value of $25 \mathrm{AU} / \mathrm{ml}$ was used. RF was quantified using an ELISA-based IgM-specific technique (cutoff value, $24 \mathrm{IU} / \mathrm{ml}$ ) as previously described (DLD Diagnostika, Hamburg, Germany) [39]. CRP and erythrocyte sedimentation rate (ESR) were characterized using standard techniques [39]. SE was defined by HLA-DRB1 alleles with HLA-DRB1 chain residues 67Leu-69Glu-71Lys/Arg-74Ala-86Gly/Val and characterized using standard techniques (Dynal, Oslo, Norway; GenoVision, Vienna, Austria; PROTRANS, Ketsch, Germany) [39, 40].

Table 1 Baseline characteristics of patients and healthy controls

\begin{tabular}{llll}
\hline Characteristics & RA $(n=178)$ & axSpA $(n=126)$ & HC $(n=119)$ \\
\hline Age, years, mean \pm SD & $55.0 \pm 12.4$ & $44.3 \pm 8.4$ & $55.2 \pm 13.5$ \\
Female sex, $n$ (\%) & $148(78.3)$ & $82(65.1)$ & $93(78.2)$ \\
Disease duration, years, median (IQR) & $5.4(1.4-11.2)$ & $4.5(2.1-5.5)$ & NA \\
G0/G1 ratio, median (IQR) & $1.25(1.09-1.56)$ & $0.89(0.79-1.09)$ & $0.95(0.77-1.13)$ \\
CRP, mg/L, mean \pm SD & $19.4 \pm 30.6^{\mathrm{a}}$ & $5.8 \pm 10.3$ & $\mathrm{NA}$ \\
DAS28, mean \pm SD & $5.1 \pm 1.4^{\mathrm{a}}$ & $\mathrm{NA}$ & $\mathrm{NA}$ \\
ACPA-positive, $n(\%)$ & $96(53.9)$ & $\mathrm{NA}$ & $\mathrm{NA}$ \\
RF-positive, $n(\%)$ & $136(76.4)$ & $\mathrm{NA}$ & $\mathrm{NA}$ \\
HLA-DRB1 SE-positive, $n(\%)$ & $96(53.9)$ & $\mathrm{NA}$ & $\mathrm{NA}$ \\
HLA-B27-positive, $n(\%)$ & $\mathrm{NA}$ & $\mathrm{NA}(69.8)$ & $\mathrm{NA}$ \\
Previous/ongoing RA therapy, $n$ (\%) & $\mathrm{NA}$ \\
\hline
\end{tabular}

Abbreviations: RA Rheumatoid arthritis, axSpA Axial spondyloarthritis, HC Healthy control subjects, G0/G1 ratio Ratio of agalactosylated to monogalactosylated immunoglobulin G, CRP C-reactive protein, DAS28 Disease Activity Score in 28 joints, ACPA Anticitrullinated protein antibody, RF Rheumatoid factor, HLA Human leukocyte antigen, SE Shared epitope, NA Not applicable

${ }^{\text {a }}$ Data available in 173 patients 


\section{Glycan characterization}

Analysis of IgG-Fc $\mathrm{N}$-glycans was performed as described previously [41] with minor modifications. Briefly, IgG was isolated from human serum using protein A Sepharose. IgG-Fc glycopeptides were separated from IgG antigenbinding fragment by pepsin digestion and isolated by ultrafiltration. After denaturation, IgG-Fc $N$-glycans were released by peptide:N-glycosidase F (Roche Applied Science, Indianapolis, IN, USA) digestion, separated with reversedphase Supelco SP20SS resin microcolumns (Sigma-Aldrich, St. Louis, MO, USA) and subsequently desalted with graphite microcolumns (Agilent Technologies, Santa Clara, CA, USA). $\mathrm{N}$-glycans were derivatized by methylation of carboxylic acid groups of terminal sialic acids to neutralize their negative charges, followed by purification to remove excess reagents. Subsequently, dried eluates were labeled with 8-aminopyrene-1,3,6-trisulfonic acid (APTS) (SigmaAldrich) at $55^{\circ} \mathrm{C}$ for $2 \mathrm{~h}$ in darkness. Capillary electrophoresis of labeled $\mathrm{N}$-glycans was performed on a Beckman P/ ACE MDQ system equipped with laser-induced fluorescence detection (Beckman Coulter, Brea, CA, USA). Separation was achieved with reversed polarity on polyvinyl alcohol-coated capillaries (50 $\mu \mathrm{m}$ inner diameter, 50-cm effective separation length from injection to detector; Beckman Coulter) using the background electrolyte (Beckman Coulter). APTS-labeled maltose was used as an internal standard to normalize detected migration time. Migration time was expressed in glucose units using an APTS-labeled dextran hydrolysate ladder. Electropherogram quality was evaluated by intensities and signal-to-noise ratio of peaks detected in all samples. Data analysis was performed with 32 Karat 8.0 software (Beckman Coulter). Structural assignment of IgG-Fc glycans was performed as reported previously. In this study 22 peaks were detected, which represent 29 glycan structures. Relative intensities were calculated after normalization as the ratio of areas between individual peaks to all peaks. In peaks with relevant comigration, the $\mathrm{N}$-glycan structure of the dominant peak defined the galactosylation type. Glycosylation traits were quantified by summing the corresponding peak areas, where the abbreviations depict the number of antennary $N$-acetylglucosamine (GlcNAc) (A), bisecting GlcNAc (B), core fucose $(\mathrm{F})$, galactose $(\mathrm{G} 1, \mathrm{G} 2)$, and sialic acids $(\mathrm{S} 1, \mathrm{~S} 2)$ (Fig. 1): agalactosylation (G0) = A2 + A2B + FA2 + FA2B; monogalactosylation $(\mathrm{G} 1)=\mathrm{A} 2[3] \mathrm{G} 1+\mathrm{A} 2 \mathrm{~B}[3] \mathrm{G} 1+$ FA2[6]G1 + FA2[3]G1 + FA2B[6]G1 + FA2B[3]G1 + $\mathrm{A} 2[3] \mathrm{G} 1 \mathrm{~S} 1+\mathrm{FA} 2[6] \mathrm{G} 1 \mathrm{~S} 1+\mathrm{A} 2 \mathrm{~B}[3] \mathrm{G} 1 \mathrm{~S} 1+\mathrm{FA} 2[3] \mathrm{G} 1 \mathrm{~S} 1$; and $\mathrm{G} 0 / \mathrm{G} 1$ ratio $=(\mathrm{G} 0) /(\mathrm{G} 1)$. Because $\mathrm{G} 0$ and $\mathrm{G} 1$ represent over $70 \%$ of total IgG-Fc glycosylation, the IgG G0/G1 ratio was used to characterize aberrant IgG galactosylation as described previously for analyses on whole serum $\mathrm{N}$-glycans as well as purified IgG [27]. Additionally, data on the main findings are presented for $\mathrm{G} 0 \%$, which represents the percentage of $\mathrm{G} 0$ among total IgG glycans.

\section{Analysis of beta 1-4 galactosyltransferase activity in B} cells and plasma cells

Beta 1-4 galactosyltransferase (B4GALT3) activity was estimated from transcriptome data for B-cell development (Gene Expression Omnibus accession number [GEO:GSE19599]) and differentiation to plasma cells (Gene Expression Omnibus accession number [GEO:GSE12366]) using data from the Gene Expression Omnibus (GEO) online repository [42, 43]. The respective data of this repository were derived from two independently pooled samples of each cell population that have subsequently been hybridized onto Applied Biosystems GeneChip Human Genome U133 Plus 2.0 microarrays (Thermo Fisher Scientific, Waltham, MA, USA). Array data have been uploaded into the BioRetis database (www.bioretis.de), and normalized signal intensities as well as group analyses have been tested.

\section{Statistical analysis}

Statistical analyses were performed using IBM SPSS Statistics 23.0 (IBM, Armonk, NY, USA) and Prism 6.0 software (GraphPad Software, La Jolla, CA, USA). The Kruskal-Wallis test followed by Dunn's multiple comparisons test, the Wilcoxon rank-sum test, and the MannWhitney $U$ test were used to analyze differences between groups. Associations between IgG G0/G1 ratio and disease-related parameters were evaluated by regression analysis. For secondary analyses (i.e., analyses of different IgG hypogalactosylation between RA subgroups defined by ACPA, RF, and SE as well as different relationships between IgG hypogalactosylation and activity markers in dependence of ACPA, RF, and SE), $p$ values after Bonferroni correction for multiple testing assuming 12 secondary hypotheses are given.

\section{Results}

\section{IgG G0/G1 ratio in $\mathrm{RA}$, axSpA, and $\mathrm{HC}$}

In patients with RA, IgG G0/G1 (median, 1.25; IQR, 1.09-1.56) was significantly higher than in $\mathrm{HC}(0.95$; $0.77-1.13)(p<0.0001)$ and axSpA $(0.89 ; 0.79-1.09)(p<$ 0.0001) (Fig. 2). Whereas axSpA exhibited inflammatory activity as measured by elevated CRP level, in HC acute or recent inflammatory processes were excluded. The patients with axSpA did not differ from $\mathrm{HC}$ in terms of IgG G0/G1 ratios, supporting the hypothesis that inflammation is not a sufficient precondition for IgG hypogalactosylation. The RA cohort exhibited age and sex distributions similar to those of HC. However, the axSpA cohort differed considerably from RA and $\mathrm{HC}$ with respect to age and sex. Thus, analyses stratified by age as well as logistic regression analyses adjusting for age and sex as possible confounders were performed. We analyzed the differences in IgG G0/G1 ratio between RA 


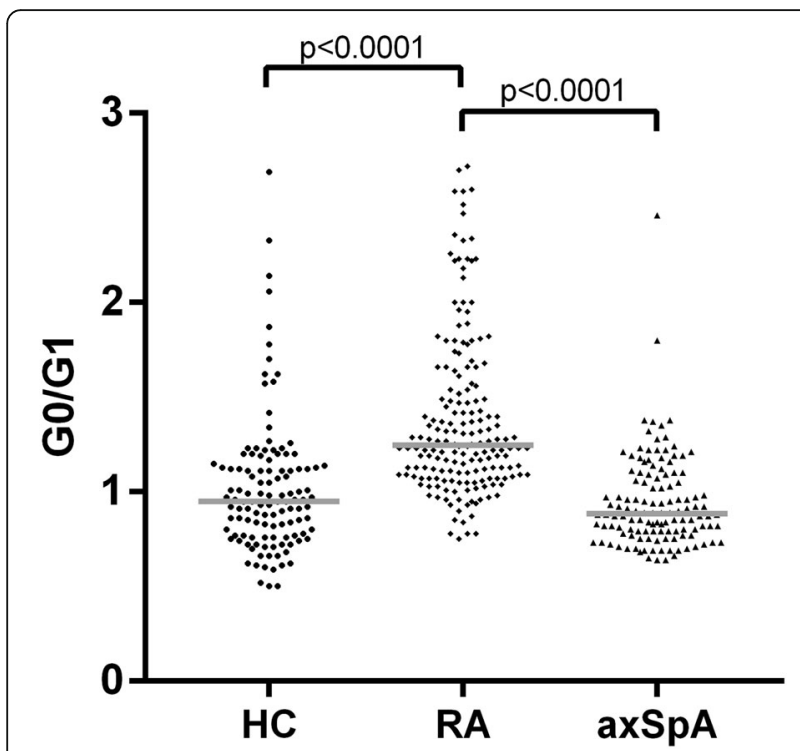

Fig. 2 Immunoglobulin G (lgG) galactosylation in patients with rheumatoid arthritis (RA), patients with axial spondyloarthritis (axSpA), and healthy control subjects ( $\mathrm{HC}$ ). Comparison of agalactosylated immunoglobulin G/monogalactosylated immunoglobulin G (GO/G1) ratios in RA ( $n=178)$, axSpA $(n=126)$, and HC $(n=119)$ is shown. Horizontal lines indicate median of distribution. $p$ Values derived by Mann-Whitney $U$ test are indicated

and axSpA in age categories ( $\leq 25$ years, $25-45$ years, $45-65$ years, $>65$ years). In all age categories, RA exhibited higher IgG G0/G1 ratios than axSpA. These differences in IgG G0/G1 ratios reached statistical significance in patients aged 25-45 years (median [IQR], RA, 1.17 [1.00-1.29]; axSpA, 0.83 [0.73-0.95]; $p<$ 0.0001 ) and 45-65 years (RA, 1.25 [1.09-1.59]; axSpA, $1.03[0.85-1.21] ; p<0.0001)$. In the small group of patients aged $\leq 25$ years (five patients with RA, two patients with axSpA), a nonsignificant trend was found (RA, 1.27 [1.23-1.40]; axSpA, individual IgG G0/G1 ratios 0.75 and $0.82 ; p=0.053)$. In patients aged $>65$ years (46 patients with RA, 2 patients with axSpA), the nonparametric comparison was nonsignificant (RA, 1.40 [1.16-1.79]; axSpA, individual IgG G0/G1 ratios 1.19 and $1.37 ; p=0.66$ ). When we compared RA, axSpA, and $\mathrm{HC}$ in a regression model, IgG hypogalactosylation was significantly more pronounced in RA than in axSpA and $\mathrm{HC}$ even after correction for age and sex as possible confounders ( $p<0.001$ for both comparisons). Plots for IgG G01/G1 ratio over age in all study cohorts are shown in Fig. 3.

An age- and sex-corrected comparison of G0\% between RA and axSpA or HC confirmed significantly higher IgG hypogalactosylation in RA than in axSpA or HC $(p<0.001$ for both comparisons; G0\% median [IQR], RA, 41.5 [38.2-47.2]; HC, 35.4 [29.6-40.4]; axSpA, 32.5 [28.6-38.0]).

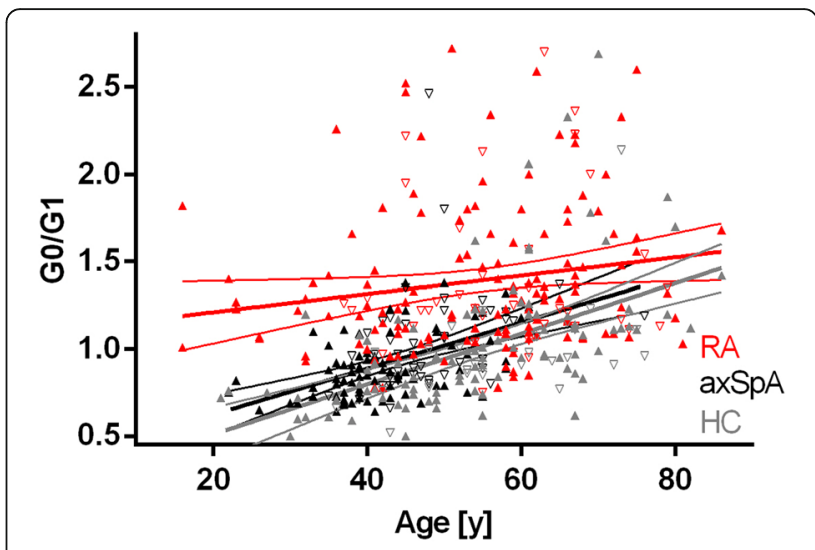

Fig. 3 Immunoglobulin G (IgG) galactosylation in patients with rheumatoid arthritis (RA), patients with axial spondyloarthritis (axSpA), and healthy control subjects $(\mathrm{HC})$ in dependency on age. Comparison of agalactosylated immunoglobulin $\mathrm{G}$ /monogalactosylated immunoglobulin $\mathrm{G}(\mathrm{GO} / \mathrm{G} 1)$ ratios over age in RA $(n=178)$, axSpA $(n=$ $126)$, and $\mathrm{HC}(n=119)$ is shown. Results of regression analyses and $95 \%$ Cls are given. $p<0.001$ for RA vs axSpA as well as RA vs HC. Data points for RA, axSpA, and HC are given in red, black, and gray, respectively; sex is indicated by upright triangles (female) and inverted triangles (male)

In the RA cohort, we tested whether disease duration would influence the IgG G0/G1 ratio. When patients were categorized in quartiles of disease duration (median [minimum-maximum], first quartile, 6 months [1 week-17 months]; second quartile, 2.6 years [1.5-5.2 years]; third quartile, 7.6 years [5.3-10.6 years]; fourth quartile, 16.6 years [10.9-60.8 years]), nonparametric testing revealed no trend for higher IgG G0/G1 ratio with increasing disease duration $(p=0.64)$. However, when the different quartiles of disease duration were considered separately, the first quartile exhibited a relatively high IgG G0/G1 ratio, followed by a significant decline in the second quartile and a re-increase of IgG G0/ G1 ratio in the third and fourth quartiles (IgG G0/G1 ratio, median [IQR], first quartile, 1.36 [1.17-1.82]; second quartile, 1.19 [1.08-1.35]; third quartile, 1.2 [1.071.54]; fourth quartile, 1.31 [1-17-1.73]).

When patients with RA were differentiated by previously untreated and treated patients, no difference with respect to IgG hypogalactosylation could be found between groups $(p=0.74)$. When we looked at specific drugs, those patients treated with sulfasalazine $(n=47)$ exhibited significantly less IgG hypogalactosylation than patients treated without sulfasalazine $(n=131)$ (IgG G0/ G1, median $[\mathrm{IQR}]$, treated with sulfasalazine, 1.16 [1.071.29]; treated without sulfasalazine, 1.31 [1.1-1.66], $p=$ 0.001; G0\%, treated with sulfasalazine, 40.1 [37.3-42.5]; treated without sulfasalazine, 42.9 [38.6-49.5], $p=$ 0.003). This finding remained statistically significant after correction for age, sex, and CRP level $(p=0.009$ for IgG G0/G1 ratio as well as G0\%). In contrast, methotrexate, leflunomide, hydroxychloroquine, and tumor 
necrosis factor inhibitors did not exhibit altered IgG galactosylation.

\section{IgG G0/G1 ratio in $\mathrm{RA}$ and axSpA in relation to CRP level}

We compared RA and axSpA with respect to IgG G0/ G1 ratio after stratifying for different CRP levels $(<5$ $\mathrm{mg} / \mathrm{L}, 5-10 \mathrm{mg} / \mathrm{L}, 10-15 \mathrm{mg} / \mathrm{L}$, and $>15 \mathrm{mg} / \mathrm{L}$ ) (Fig. 4). This analysis showed that across all CRP categories in patients with RA, significantly higher IgG G0/G1 ratios were present than in patients with axSpA (CRP $<5 \mathrm{mg}$ / L, RA, 1.18 [1.04-1.29], vs axSpA, 0.86 [0.78-0.97], $p<$ 0.0001; CRP 5-10 mg/L, RA, 1.17 [1.07-1.37], vs axSpA, 0.96 [0.82-1.09], $p=0.0002$; CRP $10-15 \mathrm{mg} / \mathrm{L}, \mathrm{RA}, 1.33$ [1.08-1.79], vs axSpA, 1.05 [0.70-1.19], $p=0.0056$; CRP $>15 \mathrm{mg} / \mathrm{L}, \mathrm{RA}, 1.61$ [1.27-2.20], vs axSpA, 1.10 [0.891.24], $p=0.0003)$. Furthermore, a significant increase in IgG G0/G1 ratio with increasing CRP levels could be observed in RA but not in axSpA (Fig. 4). The difference in IgG hypogalactosylation as measured by IgG G0/G1 ratio as well as G0\% between RA and axSpA was significant after adjustment for possible confounders (CRP, age, and sex) $(p<0.001)$ (Fig. 5).

IgG G0/G1 ratio in relation to ACPA, RF and HLA-DRB1 SE The IgG G0/G1 ratio was tested in RA in dependency of the presence or absence of ACPA, RF, and SE. As shown in Fig. 6a, in ACPA-positive RA, the IgG G0/ G1 ratio was significantly higher (1.32 [1.10-1.74]) than in ACPA-negative RA $(1.22[1.08-1.42])(p=$ $0.034)$. This relatively small difference was significant in multivariate analyses adjusting for possible confounders (CRP, age, and sex) for IgG G0/G1 ratio ( $p$ $<0.02)$ and for G0\% $(p<0.05$; median [IQR], ACPA- positive, 42.9 [38.1-50.6]; ACPA-negative, 40.5 [38.344.9]). There was only a nonsignificant trend toward higher IgG G0/G1 ratio in HLA-DRB1 SE carriers (1.27 [1.12-1.68]) compared with noncarriers (1.22 [1.07-1.44] $)(p=0.09)$. IgG galactosylation in RFpositive (1.27 [1.08-1.57]) and RF-negative RA (1.23 [1.11-1.58]) was essentially the same $(p=0.81)$.

Subsequently, we studied IgG G0/G1 ratio in RA subsets defined by combinations of SE and ACPA status (Fig. 6b). Interestingly, in SE-positive/ACPA-negative $\mathrm{RA}$, the IgG G0/G1 ratio (1.25 [1.17-1.66]) was largely comparable to both ACPA-positive subsets (ACPA-positive/SE-negative, 1.32 [1.17-1.64]; ACPApositive/SE-positive, 1.30 [1.07-1.77]). In SE-negative/ ACPA-negative RA, the IgG G0/G1 ratio (1.13 [1.051.35]) was significantly lower than in all other RA subsets. RA subsets defined by $\mathrm{SE}$ and RF status exhibited quite comparable IgG G0/G1 ratios (Fig. 6c). If considering a multiple testing strategy, Bonferroni correction would indicate only a trend.

\section{IgG G0/G1 ratio in axSpA subsets}

The axSpA cohort was also evaluated considering two subgroups, AS and nr-axSpA (Fig. 7). In AS, we observed significantly higher IgG G0/G1 ratios (0.93 [0.81-1.16]) than in nr-axSpA $(0.85$ [0.75-0.97]) $(p=$ 0.02 ). However, when adjusted for potentially confounding factors (sex and age), the difference in IgG G0/G1 ratio between AS and nr-axSpA was not statistically significant $(p=0.18)$. In addition, patients with nr-axSpA showed a significantly lower IgG G0/G1 ratio than HC $(p<0.02)$. Again, this difference did not survive adjustment for sex and age. There was a

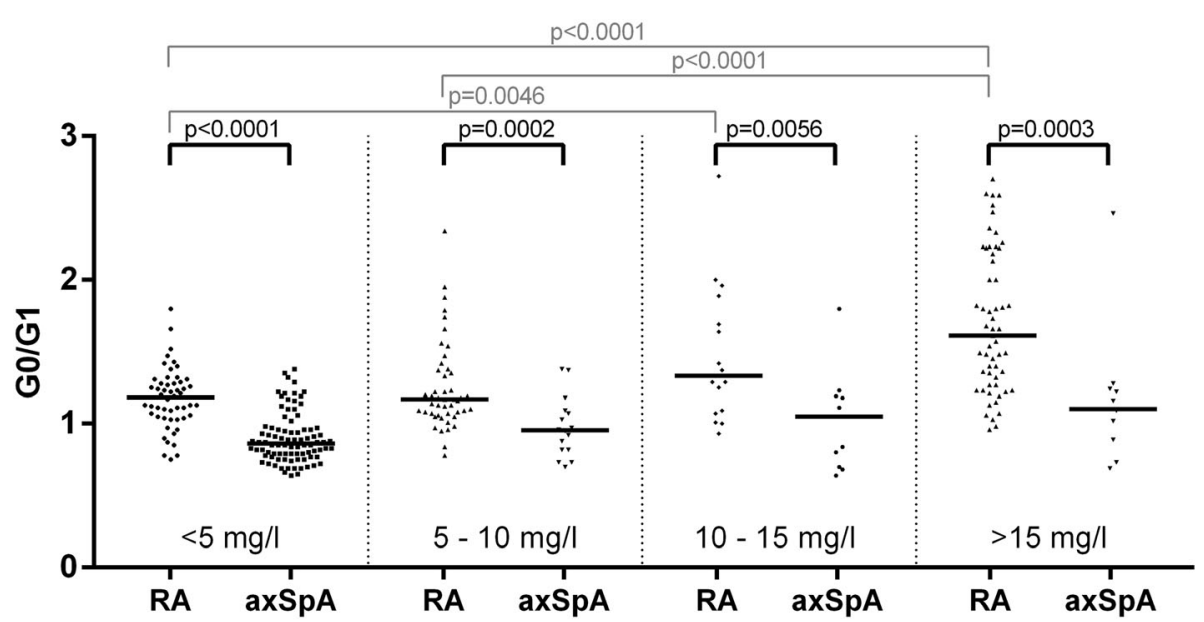

Fig. 4 Immunoglobulin G galactosylation in patients with rheumatoid arthritis (RA) and patients with axial spondyloarthritis (axSpA) in different Creactive protein (CRP)-level categories. Comparison of agalactosylated immunoglobulin G/monogalactosylated immunoglobulin G (G0/G1) ratios in RA $(n=173)$ and axSpA $(n=126)$ categorized by increasing CRP levels. Horizontal lines indicate the median of distribution. $p$ Values derived by Mann-Whitney $U$ test are indicated 

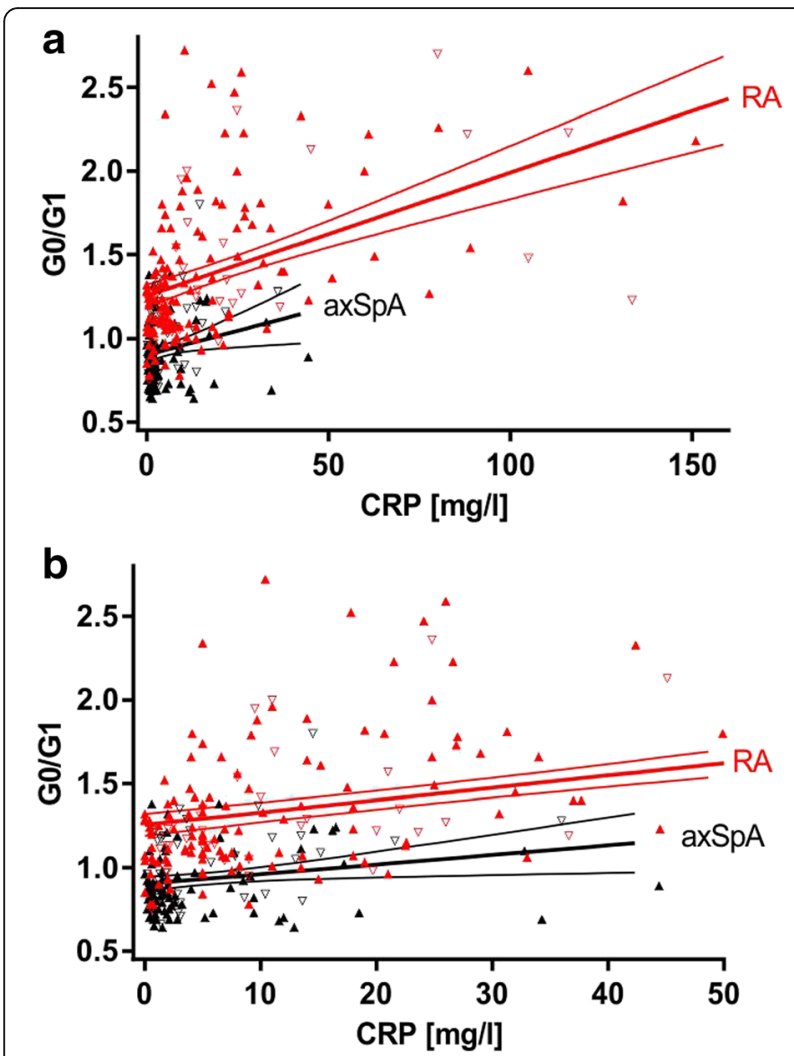

Fig. 5 Immunoglobulin $\mathrm{G}$ galactosylation in patients with rheumatoid arthritis (RA) and patients with axial spondyloarthritis (axSpA) in dependency on C-reactive protein (CRP). Comparison of agalactosylated immunoglobulin $\mathrm{G}$ /monogalactosylated immunoglobulin $\mathrm{G}(\mathrm{G} 0 / \mathrm{G} 1)$ ratios (a) over the complete CRP level or (b) over the CRP level $<50 \mathrm{mg} / \mathrm{L}$ in RA $(n=173)$ and axSpA $(n=126)$. Results of regression analyses and $95 \%$ Cls are given. $p<0.001$ for RA vs axSpA. Data points for RA and axSpA are given in red and black, respectively; sex is indicated by upright triangles (female) and inverted triangles (male)

statistically nonsignificant trend toward lower IgG G0/ G1 ratios in HLA-B27 carriers (0.87 [0.77-1.13]) than in noncarriers $(0.96[0.79-1.18])(p=0.07)$ (Fig. 7).

\section{Beta 1-4 galactosyltransferase 3 transcription in B cells and plasma cells}

Representative transcriptomic data for comparison of the enzymatic activity involved in sugar modification of immunoglobulins were selected from the GEO database. Table 2 shows not only that transcripts for B4GALT3, the enzyme responsible for the beta 1-4 galactosylation of IgG, is expressed about threefold higher in plasma cells than in naive $B$ cells but also that other transcripts of glycosyltransferases related to posttranslational modification of immunoglobulins are significantly increased in plasma cells compared with B cells.
Relationship between IgG G0/G1 ratio and disease activity in RA

IgG G0/G1 ratio was correlated with Disease Activity Score in 28 joints (DAS28), CRP, and ESR $(p<0.0001$ for all tests). Analyses regarding ACPA, RF, and SE status confirmed these results in all RA subsets (data not shown).

When we compared the correlation between IgG G0/ G1 ratio and RA disease activity (DAS28, CRP, and ESR) stratified by SE, ACPA, or RF, we identified a significant heterogeneity with respect to the presence or absence of SE and RF (Fig. 8). Stratified by SE, the correlations between IgG G0/G1 ratio and DAS28 $\left(p=0.04, p_{\text {Bonferroni }}\right.$ $=0.48), \operatorname{CRP}\left(p=0.0003, p_{\text {Bonferroni }}=0.0036\right)$, or $\operatorname{ESR}(p$ $=0.03, p_{\text {Bonferroni }}=0.36$ ) were significantly different in SE carriers and noncarriers. In general, HLA-DRB1 SE carriers exhibited a stronger correlation of IgG G0/G1 ratio with disease activity than noncarriers (Fig. $8 \mathrm{a}-\mathrm{c}$ ). Surprisingly, when we assessed these relationships between ACPA-positive and ACPA-negative RA, only a nonsignificant trend for heterogeneity could be detected (Fig. 8d-f). When we considered RF status, the correlation between IgG G0/G1 ratio and CRP was significantly stronger in RF-negative than in RF-positive RA ( $p$ $<0.0001, p_{\text {Bonferroni }}<0.0012$ ) (Fig. 8g-i). When we classified patients as seronegative (RF-negative and ACPAnegative) or seropositive (RF-positive and/or ACPApositive), the relationship between IgG G0/G1 ratio and CRP was significantly stronger in seronegative than in seropositive RA $\left(p<0.0001, p_{\text {Bonferroni }}<0.0012\right)$ (Fig. 9).

\section{Discussion}

In this study, IgG hypogalactosylation was found to be related to RA, whereas axSpA presented with levels comparable to $\mathrm{HC}$ (Fig. 2). Inflammatory activity as measured by CRP was related to increased IgG hypogalactosylation in RA but had only marginal effects in axSpA (Figs. 4 and 5). IgG hypogalactosylation was higher in RA than in axSpA and $\mathrm{HC}$ when age was considered as a confounding factor, with a tendency toward convergence after the sixth decade of life (Fig. 3). Overall, there was no trend for a continuous increase of IgG hypogalactosylation with increasing disease duration.

Hypogalactosylation of IgG in RA was first observed decades ago and is also found in other chronic inflammatory conditions [44]. Whether this phenomenon is related solely to aberrant $N$-glycan formation during IgG synthesis [45] or to the use of alternative B-cell/plasma cell subsets [46], or whether altered $N$-glycan degradation makes some contribution, is unknown [47-49]. The increase of IgG agalactosylated glycoforms in RA has been discussed as being directly associated with reduced galactosyltransferase (GTase) activity in lymphocytes [47]. Previous studies have shown a possible 

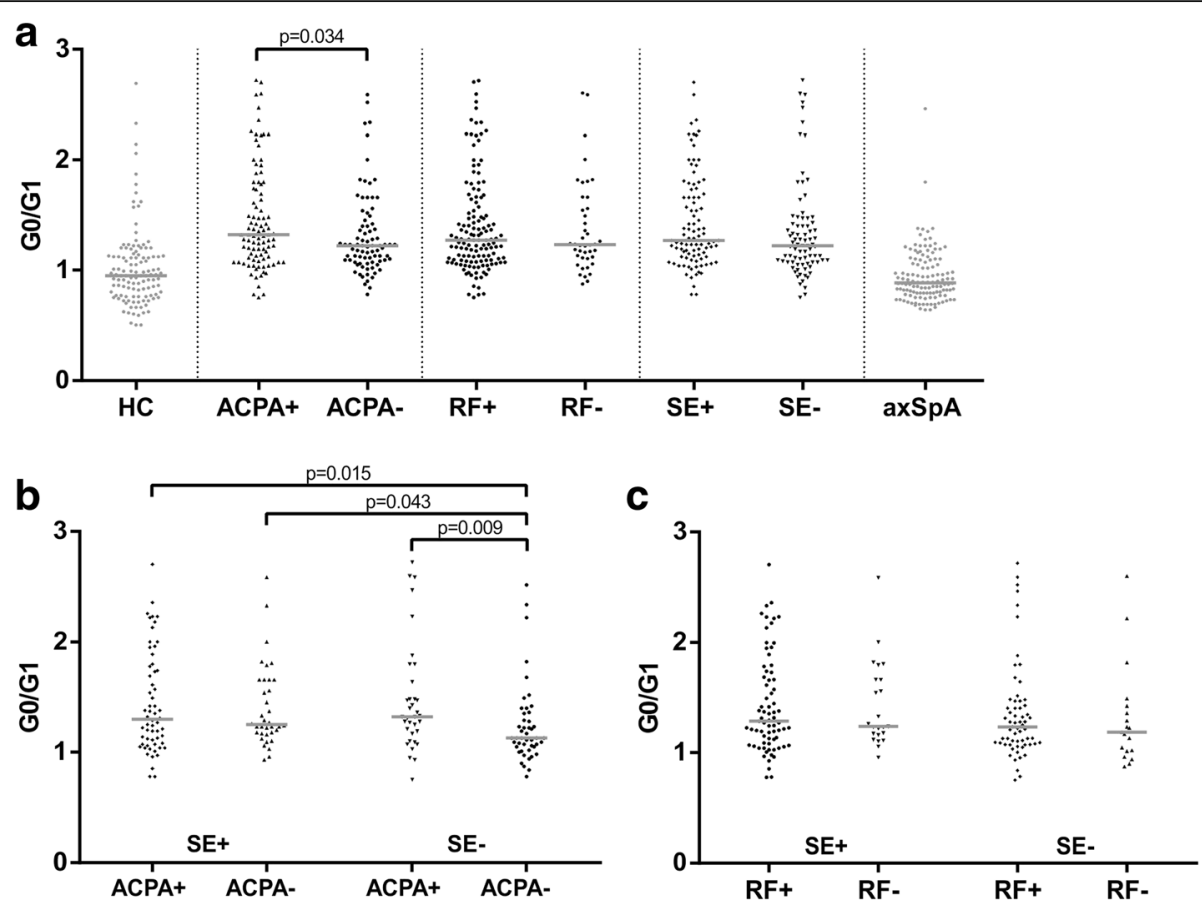

Fig. 6 Immunoglobulin G (lgG) galactosylation in rheumatoid arthritis (RA), stratified by anticitrullinated protein antibody (ACPA), rheumatoid factor (RF) and human leukocyte antigen (HLA)-DRB1 shared epitope (SE) status. Comparison of agalactosylated immunoglobulin G/ monogalactosylated immunoglobulin G (GO/G1) ratios in RA subsets defined by ACPA, RF, and HLA-DRB1 SE status. a lgG G0/G1 ratios in RA subsets defined by ACPA, RF, or SE status. $\mathbf{b} \operatorname{lgG} \mathrm{GO} / \mathrm{G} 1$ ratios of RA subsets defined combinations of SE and ACPA status. c IgG G0/G1 ratios of RA subsets defined by combinations of SE and RF status. Horizontal lines indicate the median of distribution. $p$ Values derived by Mann-Whitney $U$ tests are indicated. In regard to multiple testing, a Bonferroni-corrected $p$ value of $p<0.0042$ should be applied. axSpA Axial spondyloarthritis, HC Healthy control subjects

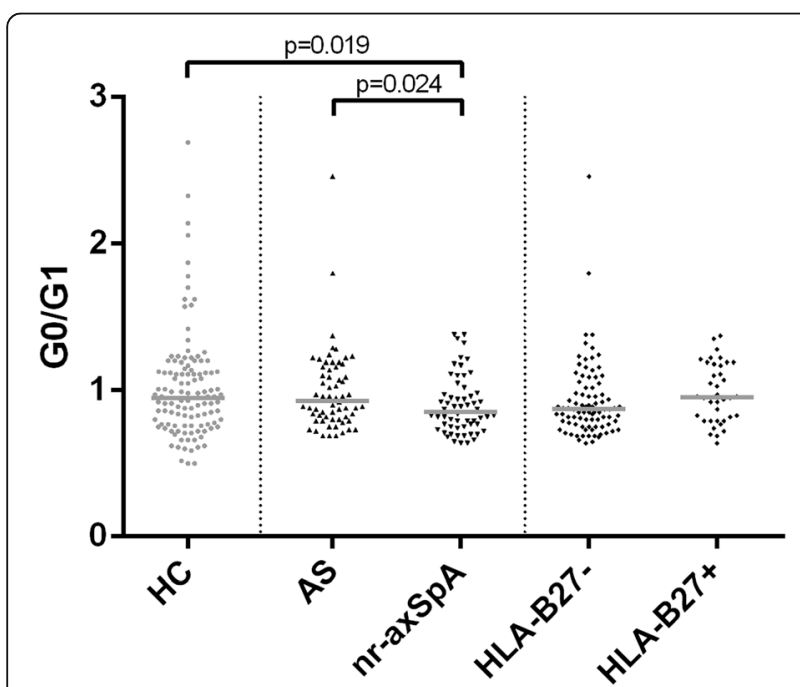

Fig. 7 Immunoglobulin G (IgG) galactosylation in subgroups of axial spondyloarthritis (axSpA). Comparison of IgG agalactosylated immunoglobulin $\mathrm{G}$ /monogalactosylated immunoglobulin G (G0/ G1) ratios in axSpA subsets defined ankylosing spondylitis (AS)/ nonradiographic axial spondyloarthritis (nr-axSpA) or human leukocyte antigen (HLA)-B27 status. Horizontal lines indicate the median of distribution. $p$ Values derived by Mann-Whitney $U$ tests are indicated. HC Healthy control subject mechanism for posttranslational regulation of GTase activity in RA. Thus, in RA, either qualitative and quantitative changes of GTase expression could result in altered enzymatic activity or the activity of specific Bcell/plasma cell subsets with preference for agalactosylated IgG is increased in RA [46].

Our findings suggest that triggering of the humoral response is necessary for changes in IgG galactosylation, or at least that inflammation itself is not a sufficient precondition in this respect. This is further supported by transcriptomic data (Table 2) that show that B cells, before differentiating to plasma cells, express lower levels of enzymes involved in glycosylation of immunoglobulins, in particular B4GALT3, the key enzyme of IgG galactosylation. This supports the assumption of increased IgG hypogalactosylation in newly triggered humoral response. The phenomenon of IgG hypogalactosylation in our study could be overlaid by age, sex, and inflammation related effects in all three groups, RA, axSpA and HC.

The finding that patients treated with sulfasalazine showed significantly decreased IgG hypogalactosylation compared with those without sulfasalazine treatment seemed surprising because the specific mode of therapeutic action of this drug is mainly unknown. However, 
Table 2 Analysis of glycosyltransferase transcription in B cells and plasma cells

\begin{tabular}{l|c|c|c|c|c|c|c|c|c|c|c|c|c|}
\hline 210243_s_at & B4GALT3 & 232.3 & 251.5 & 313.6 & 376.4 & 301 & 370.7 & 317.3 & 289.7 & 488.2 & 1492.5 & 828.7 & 796.5 \\
\hline 203988_s_at & FUT8 & 129.7 & 177.9 & 106.5 & 132.4 & 203.2 & 151.9 & 168.3 & 151.1 & 181.3 & 948.8 & 707.8 & 411.4 \\
\hline 226538_at & MAN2A1 & 319 & 414.9 & 969.1 & 1038.1 & 1099.6 & 899.9 & 635.1 & 904.4 & 1011 & 1426 & 730.5 & 969.2 \\
\hline 201126_s_at & MGAT1 & 442.2 & 267.2 & 592.7 & 525.1 & 377.1 & 289.4 & 229.1 & 186.7 & 343.4 & 1022.7 & 565.7 & 567.6 \\
\hline 203102_s_at & MGAT2 & 1021.5 & 982.3 & 1117.6 & 1569.8 & 1042.6 & 727.2 & 1014.7 & 1123.1 & 1179.7 & 6972.3 & 5994.9 & 7047.3 \\
209764_at & MGAT3 & 9.6 & 51.1 & 38.3 & 7.1 & 80.9 & 78.8 & 122.9 & 40.1 & 101.9 & 116.2 & 139.3 & 118.8 \\
\hline 201998_at & ST6GAL1 & 389.7 & 365.1 & 980.9 & 1493.2 & 4497.9 & 3636.1 & 3271.4 & 3803.8 & 4877.1 & 16146 & 12250.2 & 10515.3 \\
\hline
\end{tabular}

\begin{tabular}{cccccccccccc}
\hline Gene & Pro & Pro & Pre & Pre & $\operatorname{Imm}$ & $\operatorname{Imm}$ & Naive & Naive & Naive Plasma Plasma Plasma \\
& B & B & B & B & B & B & B & B & B & cell & cell \\
cell
\end{tabular}

Beta 1-4 galactosyltransferase (B4GALT3) transcription and transcription of other glycosyltransferases involved in immunoglobulin modification were estimated from transcriptomic data for B-cell development (Gene Expression Omnibus accession number [GSE19599]) and differentiation to plasma cells (Gene Expression Omnibus accession number [GSE12366]). Normalized signal intensities are given. Differentiation stages included are pro-B cells, pre-B cells, immature B cells, naive B cells, and plasma cells. Each column presents independent pools as described previously [42, 43]

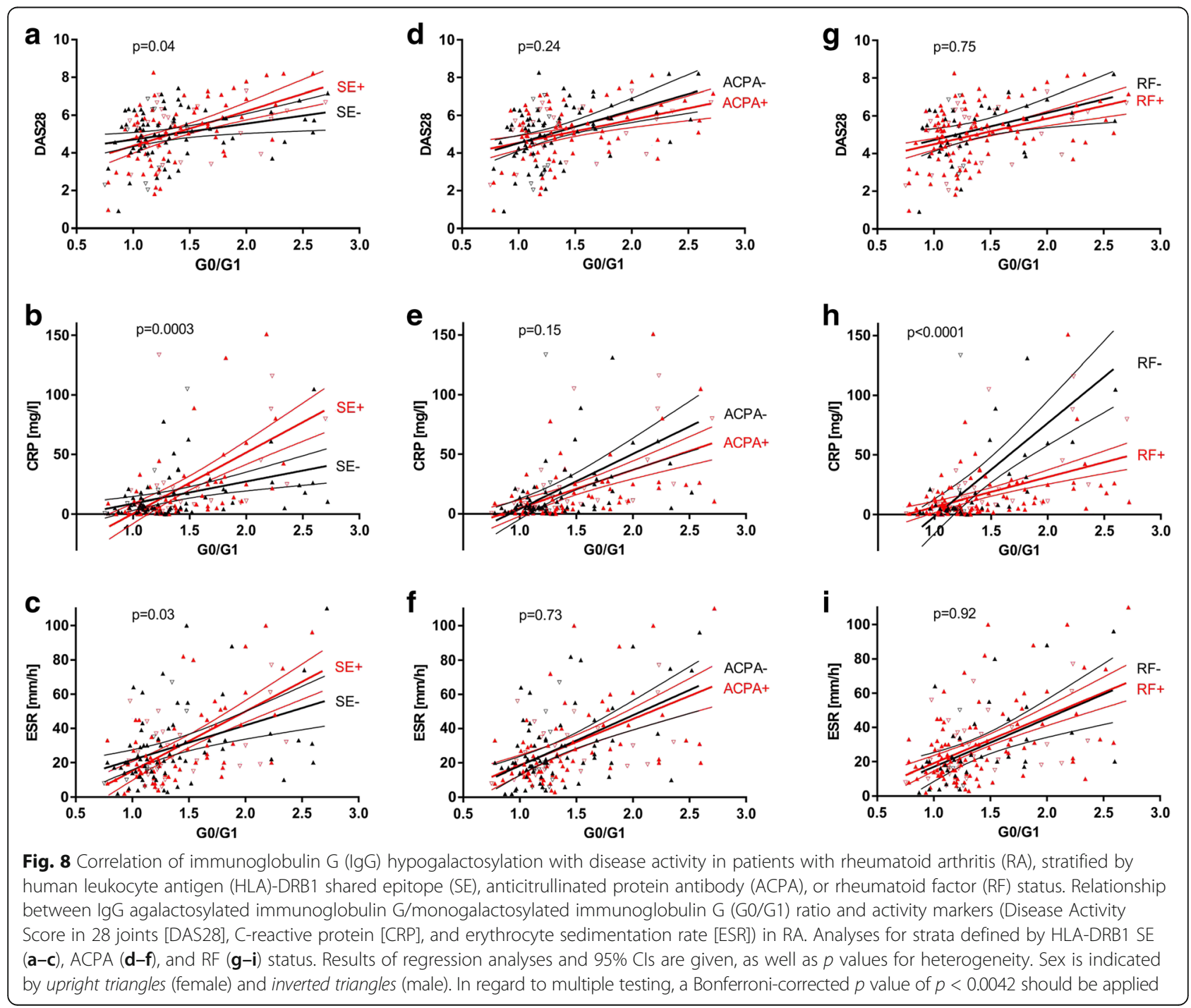



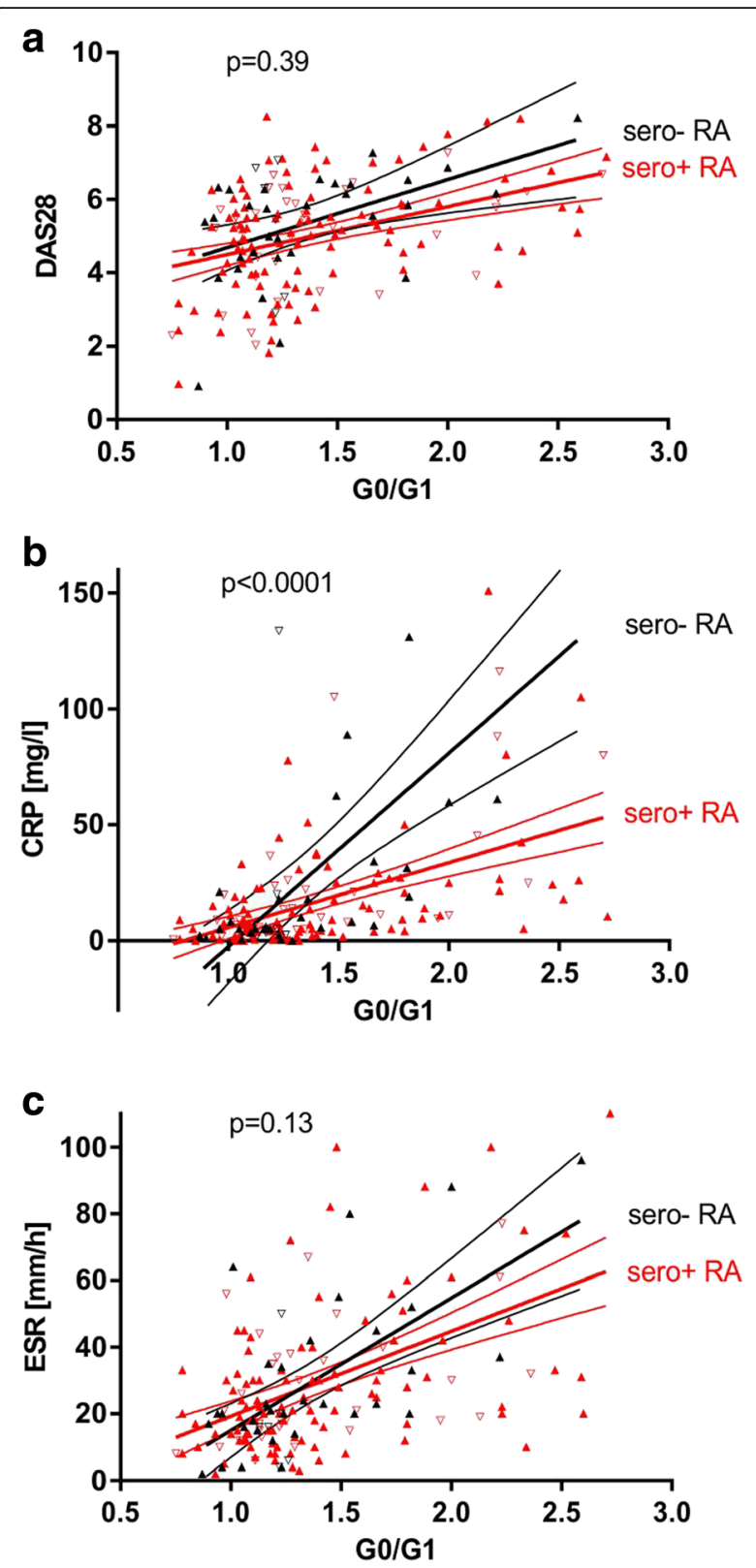

Fig. 9 Correlation of immunoglobulin $\mathrm{G}(\mathrm{lgG})$ hypogalactosylation with disease activity in seropositive and seronegative rheumatoid arthritis (RA). Relationship between IgG agalactosylated immunoglobulin G/monogalactosylated immunoglobulin G (G0/G1) ratio and activity markers ((a) Disease Activity Score in 28 joints [DAS28], (b) C-reactive protein [CRP], and (c) erythrocyte sedimentation rate $[E S R]$ ) in $\mathrm{RA}$, stratified by seropositive (sero+ anticitrullinated protein antibody [ACPA] and/or sero+ rheumatoid factor [RF]) and seronegative (sero- ACPA and sero- RF) status. Results of regression analyses and 95\% Cls are given, as well as p values for heterogeneity. Sex is indicated by upright triangles (female) and inverted triangles (male). In regard to multiple testing, a Bonferroni-corrected $p$ value of $p<0.0042$ should be applied this result is of striking compatibility with an earlier report describing reduced lymphocytic GTase activity in patients with RA and a re-increase in those patients treated with sulfasalazine [50]. On the basis of the information in this earlier report to IgG galactosylation, sulfasalazine treatment should reduce the amount of unoccupied potential galactosylation sites, thereby reducing IgG G0/G1 ratio and G0\%, which is completely in agreement with our findings.

When looking for the influence of SE, ACPA, and RF on IgG hypogalactosylation (Fig. 6), SE-negative/ ACPA-negative RA exhibited significantly less IgG hypogalactosylation than all other RA subsets, making this specific RA subset comparable to axSpA or $\mathrm{HC}$ from a glycophenotypic viewpoint. However, considering the Bonferroni correction for multiple testing qualifies these findings as trends, which should be addressed in further studies. On the other hand, IgG hypogalactosylation in SE-positive/ACPA-negative RA was at a level comparable to that in both ACPApositive strata.

Correlation between IgG hypogalactosylation and inflammatory activity in RA has been described previously $[27,29,51,52]$. Whether this relationship is due to an increased proinflammatory potential of hypogalactosylated IgG, or whether hypogalactosylation of IgG simply reflects an altered cellular activity or a shift in respective B-cell compartments (e.g., plasma cell, memory cell), is currently unknown. In our present study, the relationship between IgG hypogalactosylation and disease activity markers (Figs. 8 and 9) was dependent on SE, RF, and, with a statistically nonsignificant trend, on ACPA. The findings on the interrelationship of inflammatory activity and IgG hypogalactosylation could be interpreted as being that in seropositive RA, IgG hypogalactosylation is associated with lower CRP levels, or, in a more functional description, less inflammatory activity seems to be needed to induce aberrant IgG galactosylation. It could be considered that RF and ACPA may attenuate proinflammatory activity by capturing and eliminating the involved antigens as ICs, thereby interfering with a possible direct triggering of antigenpresenting cells and interleukin 6 as well as subsequent CRP production. Finally, association of IgG hypogalactosylation in HLA-DRB1 SE-positive patients with higher CRP levels suggests that antigen presentation in the context of SE is associated with a stronger proinflammatory immune activation prior to the involvement and differentiation of B cells, which seem to produce less IgGgalactosylating enzymes than plasma cells and thus would generate more hypogalactosylated IgG. These steps may depend on the extent of monocyte involvement, which contributes to the chronic inflammatory response by increased production, preterm release from 
bone marrow, reduced circulation time, and activation in the joint as reported recently [53]. Furthermore, HLA-DRB4, which is preferentially connected to the HLA-DRB1 SE, may exhibit differential effects on immune activation [54]. However, it should be mentioned that these interpretations are hypothetical and that the findings reported in Figs. 8 and 9 are based on analyses that could be affected by outliers and thus should be confirmed in independent studies.

The finding that in ACPA-positive RA the IgG G0/G1 ratio was significantly higher than in ACPA-negative RA (Fig. 6a), albeit losing statistical significance after correction for multiple testing, has been described previously when comparing purified anticitrullinated antibodies with repertoire IgG [27] and could be due to reduced galactosylation of ACPA. This finding would confirm the assumption that aberrant IgG galactosylation is related to altered humoral immunity [29]. Interestingly, RF status did not influence IgG G0/G1 ratio (Fig. 6a). A possible explanation could be that in RF-positive individuals, the amount of activated cell types with a preference for agalactosylated IgG is lower than in ACPA-positive individuals.

Some limitations of our study have to be mentioned. Owing to multiple testing, some findings are at risk for false-positive reporting. Our primary hypothesis was the assumption that inflammation itself is not a sufficient precondition for IgG hypogalactosylation. We think that this hypothesis is supported by our data at a sufficiently low significance level without as well as with correction for potentially confounding factors. Other findings that are based on relatively small patient subgroups should be confirmed in independent validation cohorts in the future.

\section{Conclusions}

Our data support the assumption that inflammation itself is not a sufficient precondition for aberrant IgG galactosylation and that IgG hypogalactosylation in RA is reduced by specific treatments. Whether pretreatment IgG hypogalactosylation status would help in selection of specific treatment strategies or whether assessment of IgG hypogalactosylation during therapy could help with monitoring treatment responses would be an interesting topic for further studies.

\section{Additional files}

Additional file 1: Table S1. Baseline characteristics of patient

subgroups. (DOCX 14 kb)

\section{Abbreviations}

ACPA: Anticitrullinated protein antibody; AS: Ankylosing spondylitis; axSpA: Axial spondyloarthritis; B4GALT3: Beta 1-4 galactosyltransferase 3: CRP: C-reactive protein; DAS28: Disease Activity Score in 28 joints;
ELISA: Enzyme-linked immunosorbent assay; ESR: Erythrocyte sedimentation rate; Fc: Fragment crystallizable region; G0: Agalactosylated immunoglobulin G; G1: Monogalactosylated immunoglobulin G; G2: Digalactosylated immunoglobulin G; GEO: Gene Expression Omnibus repository; GlcNAc: N-acetylglucosamine; GTase: Galactosyltransferase; HC: Healthy control subject; HLA: Human leukocyte antigen; IC: Immune complex; IgG: Immunoglobulin G; nr-axSpA: Nonradiographic axial spondyloarthritis; RA: Rheumatoid arthritis; RF: Rheumatoid factor; SE: Shared epitope

\section{Acknowledgements}

The authors thank Peggy Thiele for excellent technical assistance and Silvia Pade for support in patient recruitment and clinical and laboratory data collection.

\section{Funding}

This work was supported by the German Federal Ministry of Education and Research (Bundesministerium für Bildung und Forschung [BMBF]) through ArthroMark (grant number FKZ 01EC1009A).

\section{Availability of data and materials}

The datasets used and/or analyzed during the present study are available from the corresponding author on reasonable request.

\section{Authors' contributions}

$\mathrm{CS}, \mathrm{TH}$, and $\mathrm{BH}$ developed the hypotheses and conceived of and designed the study. CS, TH, UK, VB, GRB, DP, and BH coordinated sample acquisition and laboratory analyses. CS, TH, DP, and BH analyzed data. CS, TH, UK, GRB, DP, and $\mathrm{BH}$ interpreted the data. $\mathrm{CS}, \mathrm{TH}$, and $\mathrm{BH}$ drafted the manuscript. $\mathrm{CS}, \mathrm{TH}, \mathrm{UK}$, $\mathrm{GRB}, \mathrm{DP}$, and $\mathrm{BH}$ critically revised the manuscript for important intellectual content. All authors read and approved the final manuscript.

\section{Ethics approval and consent to participate}

This study was approved by the ethics committee of Charité Universitätsmedizin Berlin. Participants were included in the study after they provided informed consent.

\section{Consent for publication}

All authors had full access to all data and approved the final version of the manuscript for publication.

\section{Competing interests}

The authors declare that they have no competing interests.

\section{Publisher's Note}

Springer Nature remains neutral with regard to jurisdictional claims in published maps and institutional affiliations.

\section{Author details}

${ }^{1}$ Department of Rheumatology and Clinical Immunology, Charité Universitätsmedizin Berlin, Charitéplatz 1, 10117 Berlin, Germany. ${ }^{2}$ Department of Biology, Chemistry and Pharmacy, Freie Universität Berlin, Takustraße 3, 14195 Berlin, Germany. ${ }^{3}$ Institute of Transfusion Medicine, Charité - Universitätsmedizin Berlin, Charitéplatz 1, 10117 Berlin, Germany ${ }^{4}$ Institute of Laboratory Medicine, Charité - Universitätsmedizin Berlin, Augustenburger Platz 1, 13353 Berlin, Germany. ${ }^{5}$ Department of Gastroenterology, Infectiology and Rheumatology, Charité Universitätsmedizin Berlin, Hindenburgdamm 30, 12203 Berlin, Germany. ${ }^{6}$ German Rheumatism Research Centre, Charitéplatz 1, 10117 Berlin, Germany. ${ }^{7}$ Institute of Laboratory Medicine, Unfallkrankenhaus Berlin, Warener Straße 7, 12683 Berlin, Germany.

Received: 27 October 2017 Accepted: 8 February 2018 Published online: 14 March 2018

\section{References}

1. Klareskog L, Catrina Al, Paget S. Rheumatoid arthritis. Lancet. 2009; 373(9664):659-72

2. Smolen JS, Aletaha D. Challenges of predicting treatment response in patients with rheumatoid arthritis. Nat Clin Pract Rheumatol. 2005;1(2):62-3. 
3. Vencovsky J, Huizinga TW. Rheumatoid arthritis: the goal rather than the health-care provider is key. Lancet. 2006;367(9509):450-2.

4. Bukhari M, Lunt M, Harrison BJ, Scott DG, Symmons DP, Silman AJ. Rheumatoid factor is the major predictor of increasing severity of radiographic erosions in rheumatoid arthritis: results from the Norfolk Arthritis Register Study, a large inception cohort. Arthritis Rheum. 2002; 46(4):906-12.

5. Cantaert T, De Rycke L, Bongartz T, Matteson EL, Tak PP, Nicholas AP, Baeten D. Citrullinated proteins in rheumatoid arthritis: crucial...but not sufficient! Arthritis Rheum. 2006:54(11):3381-9.

6. Tan EM, Smolen JS. Historical observations contributing insights on etiopathogenesis of rheumatoid arthritis and role of rheumatoid factor. J Exp Med. 2016;213(10):1937-50

7. Hill JA, Southwood S, Sette A, Jevnikar AM, Bell DA, Cairns E. Cutting edge: the conversion of arginine to citrulline allows for a high-affinity peptide interaction with the rheumatoid arthritis-associated HLA-DRB1*0401 MHC class II molecule. J Immunol. 2003;171(2):538-41.

8. Padyukov L, Silva C, Stolt P, Alfredsson L, Klareskog L. A gene-environment interaction between smoking and shared epitope genes in HLA-DR provides a high risk of seropositive rheumatoid arthritis. Arthritis Rheum. 2004;50(10):3085-92.

9. Klareskog L, Stolt P, Lundberg K, Källberg H, Bengtsson C, Grunewald J, Ronnelid J, Harris HE, Ulfgren AK, Rantapää-Dahlqvist S, et al. A new model for an etiology of rheumatoid arthritis: smoking may trigger HLA-DR (shared epitope)-restricted immune reactions to autoantigens modified by citrullination. Arthritis Rheum. 2006;54(1):38-46.

10. Pedersen M, Jacobsen $S$, Garred P, Madsen HO, Klarlund M, Svejgaard A, Pedersen BV, Wohlfahrt J, Frisch M. Strong combined gene-environment effects in anti-cyclic citrullinated peptide-positive rheumatoid arthritis: a nationwide case-control study in Denmark. Arthritis Rheum. 2007:56(5): 1446-53.

11. Mattey DL, Dawes PT, Clarke S, Fisher J, Brownfield A, Thomson W, Hajeer AH, Ollier WE. Relationship among the HLA-DRB1 shared epitope, smoking, and rheumatoid factor production in rheumatoid arthritis. Arthritis Rheum. 2002;47(4):403-7.

12. Rudd PM, Leatherbarrow RJ, Rademacher TW, Dwek RA. Diversification of the IgG molecule by oligosaccharides. Mol Immunol. 1991;28(12):1369-78.

13. Goulabchand R, Vincent T, Batteux F, Eliaou JF, Guilpain P. Impact of autoantibody glycosylation in autoimmune diseases. Autoimmun Rev. 2014; 13(7):742-50.

14. Kobata A. The N-linked sugar chains of human immunoglobulin G: their unique pattern, and their functional roles. Biochim Biophys Acta. 2008; 1780(3):472-8.

15. Mimura Y, Church S, Ghirlando R, Ashton PR, Dong S, Goodall M, Lund J, Jefferis $R$. The influence of glycosylation on the thermal stability and effector function expression of human lgG1-Fc: properties of a series of truncated glycoforms. Mol Immunol. 2000;37(12-13):697-706.

16. Dwek RA, Lellouch AC, Wormald MR. Glycobiology: 'the function of sugar in the lgG molecule'. J Anat. 1995;187(Pt 2):279-92.

17. Arnold JN, Wormald MR, Sim RB, Rudd PM, Dwek RA. The impact of glycosylation on the biological function and structure of human immunoglobulins. Annu Rev Immunol. 2007;25:21-50.

18. Niwa R, Natsume A, Uehara A, Wakitani M, lida S, Uchida K, Satoh M, Shitara K. IgG subclass-independent improvement of antibody-dependent cellular cytotoxicity by fucose removal from Asn297-linked oligosaccharides. J Immunol Methods. 2005;306(1-2):151-60.

19. Shinkawa T, Nakamura K, Yamane N, Shoji-Hosaka E, Kanda Y, Sakurada M, Uchida K, Anazawa H, Satoh M, Yamasaki M, et al. The absence of fucose but not the presence of galactose or bisecting $\mathrm{N}$-acetylglucosamine of human IgG1 complex-type oligosaccharides shows the critical role of enhancing antibody-dependent cellular cytotoxicity. J Biol Chem. 2003; 278(5):3466-73.

20. Geijtenbeek TB, van Vliet SJ, Engering A, 't Hart BA, van Kooyk Y. Selfand nonself-recognition by C-type lectins on dendritic cells. Annu Rev Immunol. 2004;22:33-54.

21. Kaneko Y, Nimmerjahn F, Ravetch JV. Anti-inflammatory activity of immunoglobulin G resulting from Fc sialylation. Science. 2006;313(5787): 670-3.

22. Sondermann $\mathrm{P}$, Kaiser J, Jacob U. Molecular basis for immune complex recognition: a comparison of Fc-receptor structures. J Mol Biol. 2001; 309(3):737-49.
23. Maverakis E, Kim K, Shimoda M, Gershwin ME, Patel F, Wilken R, Raychaudhuri S, Ruhaak LR, Lebrilla CB. Glycans in the immune system and the altered glycan theory of autoimmunity: a critical review. J Autoimmun. 2015;57:1-13.

24. Lauc G, Pezer M, Rudan I, Campbell H. Mechanisms of disease: the human N-glycome. Biochim Biophys Acta. 2016;1860(8):1574-82.

25. Parekh RB, Dwek RA, Sutton BJ, Fernandes DL, Leung A, Stanworth D, Rademacher TW, Mizuochi T, Taniguchi T, Matsuta K, et al. Association of rheumatoid arthritis and primary osteoarthritis with changes in the glycosylation pattern of total serum IgG. Nature. 1985;316(6027):452-7.

26. Parekh R, Isenberg D, Rook G, Roitt I, Dwek R, Rademacher T. A comparative analysis of disease-associated changes in the galactosylation of serum $\operatorname{lgG}$. J Autoimmun. 1989;2(2):101-14.

27. Ercan A, Cui J, Chatterton DE, Deane KD, Hazen MM, Brintnell W, O'Donnell $\mathrm{Cl}$, Derber $L A$, Weinblatt ME, Shadick NA, et al. Aberrant IgG galactosylation precedes disease onset, correlates with disease activity, and is prevalent in autoantibodies in rheumatoid arthritis. Arthritis Rheum. 2010;62(8):2239-48.

28. Harre U, Lang SC, Pfeifle R, Rombouts $Y$, Fruhbeisser $S$, Amara K, Bang $H$, Lux A, Koeleman CA, Baum W, et al. Glycosylation of immunoglobulin $\mathrm{G}$ determines osteoclast differentiation and bone loss. Nat Commun. 2015;6:6651.

29. Ercan A, Cui J, Hazen MM, Batliwalla F, Royle L, Rudd PM, Coblyn JS, Shadick N, Weinblatt ME, Gregersen P, et al. Hypogalactosylation of serum N-glycans fails to predict clinical response to methotrexate and TNF inhibition in rheumatoid arthritis. Arthritis Res Ther. 2012;14(2):R43.

30. Rook GA, Steele J, Brealey R, Whyte A, Isenberg D, Sumar N, Nelson JL, Bodman KB, Young A, Roitt IM, et al. Changes in IgG glycoform levels are associated with remission of arthritis during pregnancy. J Autoimmun. 1991;4(5):779-94.

31. Bondt A, Rombouts $Y$, Selman MH, Hensbergen PJ, Reiding KR, Hazes JM, Dolhain RJ, Wuhrer M. Immunoglobulin G (lgG) Fab glycosylation analysis using a new mass spectrometric high-throughput profiling method reveals pregnancy-associated changes. Mol Cell Proteomics. 2014;13(11):3029-39.

32. Van Beneden K, Coppieters K, Laroy W, De Keyser F, Hoffman IE, Van den Bosch F, Vander Cruyssen B, Drennan M, Jacques P, Rottiers P, et al. Reversible changes in serum immunoglobulin galactosylation during the immune response and treatment of inflammatory autoimmune arthritis. Ann Rheum Dis. 2009;68(8):1360-5.

33. Croce A, Firuzi O, Altieri F, Eufemi M, Agostino R, Priori R, Bombardieri $M$, Alessandri C, Valesini G, Saso L. Effect of infliximab on the glycosylation of $\mathrm{lgG}$ of patients with rheumatoid arthritis. J Clin Lab Anal. 2007;21(5):303-14.

34. Nielen MM, van Schaardenburg D, Reesink HW, Twisk JW, van de Stadt RJ, van der Horst-Bruinsma IE, de Gast T, Habibuw MR, Vandenbroucke JP, Dijkmans BA. Increased levels of C-reactive protein in serum from blood donors before the onset of rheumatoid arthritis. Arthritis Rheum. 2004;50(8):2423-7.

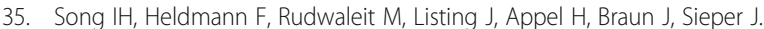
Different response to rituximab in tumor necrosis factor blocker-naive patients with active ankylosing spondylitis and in patients in whom tumor necrosis factor blockers have failed: a twenty-four-week clinical trial. Arthritis Rheum. 2010;62(5):1290-7.

36. Wendling D, Dougados M, Berenbaum F, Brocq O, Schaeverbeke T, Mazieres B, Marcelli C, Leparc JM, Bertin P, Robin M, et al. Rituximab treatment for spondyloarthritis. A nationwide series: data from the AIR registry of the French Society of Rheumatology. J Rheumatol. 2012;39(12):2327-31.

37. Arnett FC, Edworthy SM, Bloch DA, McShane DJ, Fries JF, Cooper NS, Healey LA, Kaplan SR, Liang MH, Luthra HS, et al. The American Rheumatism Association 1987 revised criteria for the classification of rheumatoid arthritis. Arthritis Rheum. 1988;31(3):315-24.

38. Rudwaleit M, Haibel H, Baraliakos X, Listing J, Marker-Hermann E, Zeidler H, Braun J, Sieper J. The early disease stage in axial spondylarthritis: results from the German Spondyloarthritis Inception Cohort. Arthritis Rheum. 2009; 60(3):717-27.

39. Hoppe B, Haupl T, Egerer K, Gruber R, Kiesewetter H, Salama A, Burmester GR, Dorner T. Influence of peptidylarginine deiminase type 4 genotype and shared epitope on clinical characteristics and autoantibody profile of rheumatoid arthritis. Ann Rheum Dis. 2009;68(6):898-903.

40. Hoppe B, Haupl T, Gruber R, Kiesewetter H, Burmester GR, Salama A, Dorner T. Detailed analysis of the variability of peptidylarginine deiminase type 4 in German patients with rheumatoid arthritis: a case-control study. Arthritis Res Ther. 2006;8(2):R34. 
41. Schwedler C, Kaup M, Petzold D, Hoppe B, Braicu El, Sehouli J, Ehlers M, Berger M, Tauber R, Blanchard V. Sialic acid methylation refines capillary electrophoresis laser-induced fluorescence analyses of immunoglobulin G N-glycans of ovarian cancer patients. Electrophoresis. 2014;35(7):1025-31.

42. Andersson A, Eden P, Olofsson T, Fioretos T. Gene expression signatures in childhood acute leukemias are largely unique and distinct from those of normal tissues and other malignancies. BMC Med Genet. 2010;3:6.

43. Longo NS, Lugar PL, Yavuz S, Zhang W, Krijger PH, Russ DE, Jima DD, Dave SS, Grammer AC, Lipsky PE. Analysis of somatic hypermutation in X-linked hyper-lgM syndrome shows specific deficiencies in mutational targeting. Blood. 2009:113(16):3706-15.

44. Watson M, Rudd PM, Bland M, Dwek RA, Axford JS. Sugar printing rheumatic diseases: a potential method for disease differentiation using immunoglobulin G oligosaccharides. Arthritis Rheum. 1999;42(8):1682-90.

45. Omtvedt LA, Royle L, Husby G, Sletten K, Radcliffe CM, Harvey DJ, Dwek RA, Rudd PM. Glycan analysis of monoclonal antibodies secreted in deposition disorders indicates that subsets of plasma cells differentially process lgG glycans. Arthritis Rheum. 2006;54(11):3433-40.

46. Alavi A, Pool AJ, Axford JS. New insights into rheumatoid arthritis associated glycosylation changes. Adv Exp Med Biol. 2005;564:129-38.

47. Axford JS, Mackenzie L, Lydyard PM, Hay FC, Isenberg DA, Roitt IM. Reduced B-cell galactosyltransferase activity in rheumatoid arthritis. Lancet. 1987; 2(8574):1486-8.

48. Furukawa K, Matsuta K, Takeuchi F, Kosuge E, Miyamoto T, Kobata A. Kinetic study of a galactosyltransferase in the $B$ cells of patients with rheumatoid arthritis. Int Immunol. 1990;2(1):105-12.

49. Keusch J, Lydyard PM, Berger EG, Delves PJ. B lymphocyte galactosyltransferase protein levels in normal individuals and in patients with rheumatoid arthritis. Glycoconj J. 1998;15(11):1093-7.

50. Axford JS, Sumar N, Alavi A, Isenberg DA, Young A, Bodman KB, Roitt IM. Changes in normal glycosylation mechanisms in autoimmune rheumatic disease. J Clin Invest. 1992;89(3):1021-31.

51. Troelsen LN, Jacobsen S, Abrahams JL, Royle L, Rudd PM, Narvestad E, Heegaard NH, Garred P. IgG glycosylation changes and MBL2 polymorphisms: associations with markers of systemic inflammation and joint destruction in rheumatoid arthritis. J Rheumatol. 2012;39(3):463-9.

52. Gindzienska-Sieskiewicz E, Klimiuk PA, Kisiel DG, Gindzienski A, Sierakowski S. The changes in monosaccharide composition of immunoglobulin $\mathrm{G}$ in the course of rheumatoid arthritis. Clin Rheumatol. 2007;26(5):685-90.

53. Smiljanovic B, Radzikowska A, Kuca-Warnawin E, Kurowska W, Grun JR, Stuhlmuller B, Bonin M, Schulte-Wrede U, Sorensen T, Kyogoku C, et al. Monocyte alterations in rheumatoid arthritis are dominated by preterm release from bone marrow and prominent triggering in the joint. Ann Rheum Dis. 2018;77(2):300-8.

54. Stuhlmuller B, Mans K, Tandon N, Bonin MO, Smiljanovic B, Sorensen TA, Schendel P, Martus P, Listing J, Detert J, et al. Genomic stratification by expression of HLA-DRB4 alleles identifies differential innate and adaptive immune transcriptional patterns - A strategy to detect predictors of methotrexate response in early rheumatoid arthritis. Clin Immunol. 2016; 171:50-61.

\section{Submit your next manuscript to BioMed Central and we will help you at every step:}

- We accept pre-submission inquiries

- Our selector tool helps you to find the most relevant journal

- We provide round the clock customer support

- Convenient online submission

- Thorough peer review

- Inclusion in PubMed and all major indexing services

- Maximum visibility for your research

Submit your manuscript at www.biomedcentral.com/submit 